Cite as: Clarke E, Puschner B, Jordan H, Williams P, Konrad J, Kawohl W, Bär A, Rössler W, Del Vecchio V, Sampogna G, Nagy M, Süveges A, Krogsgaard Bording M, Slade M (2015) Empowerment and satisfaction in a multinational study of routine clinical practice, Acta Psychiatrica Scandinavica, 131, 369-378.

\title{
Empowerment and satisfaction in a multinational study of routine clinical practice
}

Running title: Empowerment and satisfaction

Eleanor Clarke ${ }^{1}$, Bernd Puschner ${ }^{2}$, Harriet Jordan ${ }^{1}$, Paul Williams ${ }^{1}$, Jana Konrad $^{2}$, Wolfram Kawohl ${ }^{3}$, Arlette Bär ${ }^{3}$, Wulf Rössler ${ }^{3}$, Valeria Del Vecchio ${ }^{4}$, Gaia Sampogna ${ }^{4}$, Marietta Nagy ${ }^{5}$, Agnes Süveges ${ }^{5}$, Malene Krogsgaard Bording $^{6}$, Mike Slade ${ }^{*}$

${ }^{1}$ King's College London, Institute of Psychiatry, Psychology \& Neuroscience, London, United Kingdom

${ }^{2}$ Department of Psychiatry and Psychotherapy II, Section Process-Outcome Research, Ulm University, Germany

${ }^{3}$ University Hospital for Psychiatry, University of Zurich, Switzerland

${ }^{4}$ Department of Psychiatry, University of Naples SUN, Naples, Italy,

${ }^{5}$ Medical and Health Science Center, Department of Psychiatry, University of Debrecen, Debrecen, Hungary

${ }^{6}$ Unit for Psychiatric Research, Aalborg Psychiatric Hospital, Aalborg University Hospital, Aalborg, Denmark

* Corresponding author

King's College London, Section for Recovery (Box P029), Institute of Psychiatry, Psychology \& Neuroscience, De Crespigny Park, London SE5 8AF, United Kingdom. Email:mike.slade@kcl.ac.uk

Fax: +44 (0) 2072771462

Phone: +44 (0) 2078480795 


\section{ABSTRACT}

\section{Objective}

Decision-making between mental health clinicians and patients is under-researched. We tested whether mental health patients are more satisfied with a decision made (a) using their preferred decision-making style and (b) with a clinician with the same decision-making style preference.

\section{Method}

As part of the CEDAR Study (ISRCTN75841675), a convenience sample of 445 patients with severe mental illness from six European countries were assessed for desired clinical decision-making style (rated by patients and paired clinicians), decision-specific experienced style and satisfaction.

\section{Results}

Patients who experienced more involvement in decision-making than they desired rated higher satisfaction $(\mathrm{OR}=2.47, \mathrm{p}=0.005,95 \% \mathrm{Cl} 1.32$ to 4.63$)$. Decisions made with clinicians whose decision-making style preference was for more active involvement than the patient preference were rated with higher satisfaction $(\mathrm{OR}=3.17, \mathrm{p}=0.003,95 \% \mathrm{Cl} 1.48$ to 6.82$)$.

\section{Conclusion}

More active involvement in decision-making than the patient stated as desired was associated with higher satisfaction. A clinical orientation towards empowering, rather than shared, decision-making may maximise satisfaction.

Keywords

Decision Making, Mental Health 


\section{Significant outcomes}

1. Patients who were empowered (i.e. more involved in decision-making than desired) were more likely to have higher satisfaction scores

2. Decisions made with clinicians whose decision-making style preference was for more active involvement than the patient preference were rated with higher satisfaction.

3. A clinical orientation towards empowering, rather than shared, decision-making may maximise satisfaction.

\section{Limitations}

1. The convenience sample means that participants may not be representative, due to factors such as clinician bias in referral.

2. A cross-sectional study cannot differentiate cause and effect of preference, agreement and satisfaction.

3. The extent to which the decision topic impacted on preference and agreement is unknown. 


\section{Background}

Decision-making between mental health clinicians and patients is the vehicle of health care delivery (1). Clinical decision-making (CDM) is especially important for long-term decisions and chronic illness, particularly in mental health (2). Research into CDM is complex (3), involving capacity (4) and patient, clinician and family perspectives (5). Preferences are varied, for example younger people are more likely to prefer active CDM (6). Existing research has focussed on decisions made with medical doctors $(7,8)$ even though patients make decisions with clinicians from across the multi-disciplinary team.

CDM research focuses on the involvement, experience and satisfaction of the clinician and patient. Three levels of involvement in CDM have been described: informed, shared and passive $(9,10)$. Passive decision-making occurs when the clinician makes the decision for the patient. Informed (also referred to as active) decision-making occurs when the patient makes the decision, having received information from the clinician. Shared decision-making (SDM) involves collaborative decision-making. A systematic review synthesised 161 conceptual models of shared decision-making to identify eight defining characteristics of healthcare professional behaviour: define / explain the healthcare problem, present options, discuss benefits / risks / costs, clarify patient values / preferences, discuss patient ability / selfefficacy, present what is known and make recommendations, clarify the patient's understanding, and make or explicitly defer a decision (11). This framework underpinned a systematic review of implementation of SDM, identifying five RCTs of interventions to improve healthcare professionals' adoption of SDM (12). Training of healthcare professionals and decision aids (structured approaches to facilitate SDM) were tentatively recommended, though none of the studies related to mental health 
populations. A more recent systematic review of 199 analyses from 115 studies of decision-making style preference concluded that patients prefer shared to passive decision-making, with the preference proportion higher in later studies. The named clinical populations comprised cancer $(n=43)$, diabetes / asthma / hypertension / HIV / multiple sclerosis $(n=26)$, invasive procedures $(n=14)$ and 'general populations' of community samples $(n=36)(13)$.

CDM is especially under-researched in mental health. A systematic review of SDM included eleven trials of SDM interventions with only two from mental healthcare (14) - one involving inpatient treatment of schizophrenia (107 patients) (15) and one of primary care patients with depression (23 clinicians, 405 patients) (7). Since then, one randomised controlled trial also showing advantages for decision aids (80 community patients) (16) has been published. A Cochrane review of SDM in mental health concluded that "Further research is urgently needed in this area" (p.14) (17).

Despite being under-researched, SDM in mental health is widely recommended in clinical guidelines. For example, the National Institute for Health and Clinical Excellence guidelines for psychosis and schizophrenia recommend "patients should have the opportunity to make informed decisions about their care and treatment, in partnership with their healthcare professionals" (p.7) (18), and more generally in non-acute mental health settings across all diagnostic groups that "a shared decision making approach should be facilitated" (p.67) (19).

\section{Aims of the study}

The aim of this study was to test two hypotheses. The preference hypothesis was that people using mental health services will be more satisfied with a specific 
decision if it is made using their preferred decision-making style (Active, Shared or Passive). The agreement hypothesis was that people using mental health services will be more satisfied with decisions they make with a clinician with the same preferred decision-making style.

\section{Methods}

Participants

Data were collected in the baseline phase of the naturalistic longitudinal observational Clinical Decision Making and Outcome in Routine Care for People with Severe Mental Illness (CEDAR) Study (ISRCTN75841675) (20). The CEDAR study recruited mental health patients from six European countries: Denmark, Germany, Hungary, Italy, Switzerland and UK. The study sites reflect the diversity across Europe in the organization of mental health services. Ulm (Germany): The Department is responsible for the provision of mental health care in a large catchment area in rural Bavaria (population 671,000). Multidisciplinary teams (psychiatrists, psychologists, social workers, nurses, occupational therapists) offer the full range of pharmacological and psychosocial interventions in inpatient, outpatient and day care clinics. The Department collaborates closely with officebased psychiatrists and psychotherapists in the area. London (UK): The site comprised three specialist community teams: early psychosis, assertive outreach and Rehabilitation \& Recovery. All teams are multidisciplinary $(n=10-15)$, comprising clinical psychology, nursing, occupational therapy, psychiatry and social work professionals, as well as support workers and administrative staff. These teams provide a service across the London Borough of Croydon (population 330,000) as 
part of a range of services for adults aged 18 to 65 , including three community mental health teams, home treatment team, community forensic team, and in-patient beds. Naples (Italy): The Department includes inpatient and outpatient units and one day hospital. The outpatient units include specialist clinical teams for the management and treatment of psychotic disorders, mood disorders, eating disorders, obsessive-compulsive disorders. Specialist teams for early detection and management of psychoses and for cognitive and psychosocial rehabilitation are available. Debrecen (Hungary): The Department provides in- and outpatient mental health care for the city of Debrecen (population 200,000). The team is completed by an occupational therapist and a social worker professional who keeps contact with the regional rehabilitation institutions and mental homes. Aalborg (Denmark): The Psychiatry Region North includes various treatment centres, including inpatient treatment, outpatient teams and early psychosis teams. The collaborating centres in the CEDAR study were organized within Universities of Aarhus, Aalborg, Copenhagen, and Southern Denmark. Others were provincial hospitals with associations to Aarhus University. Furthermore, CEDAR collaborated with officebased psychiatrist. Zurich (Switzerland): The Department takes responsibility for a defined catchment area in Zurich City of about 390,000 inhabitants. It comprises 488 beds and additionally offers specialized care in a Centre of Psychiatric Rehabilitation, in a Crisis Centre and in another Centre of Drug Medicine.

Inclusion criteria were adults (aged 18-60 years); diagnosis of a severe mental disorder of any kind; expected contact with mental health services for the next year; sufficient command of the host countries language and capacity to consent. Exclusion criteria were a primary diagnosis of learning disability, dementia, 
substance abuse or organic brain disorder; clinician-rated cognitive impairment severe enough to prevent giving meaningful information for the measures; treatment by the forensic services. Additionally for this study patients were excluded who had not rated Satisfaction with decision. After complete description of the study to participants, written informed consent was obtained.

\section{Measures}

For screening the Structured Clinical Interview for DSM-IV Axis I Disorders - Clinical Version (SCID-CV) (SCID-CV, 21) was used to establish diagnosis. The Threshold Assessment Grid (TAG) (TAG, 22) was used to estimate severity of illness, a score $\geq 5$ indicating severe difficulties (23).

The Clinical Decision Making Style (CDMS) measure assesses decisionmaking preferences, with parallel versions for clinicians and patients (20). The CDMS Participation sub-scale comprises 15 items, each scored on a five-point scale: six rating general preferences (e.g. "I should decide for myself how often I want to see my clinician") and nine rating preferences in three clinical scenarios. The prorated mean of all items, ranging from 0 (low desire for active involvement by patient) to 4 is categorised into Passive (<1.5), Shared (1.5-2.5) or Active (>2.5). We refer to this sub-scale as the desired style (DS), for both clinician-rated (DS-S) and patient-rated DS (DS-P) forms. So for example DS-S Passive and DS-P Passive indicate agreement on preferred CDM style.

The Clinical Decision Making Involvement and Satisfaction (CDIS) measure has two sub-scales assessing the patient's involvement and satisfaction with a specific decision made with their clinician (24). The Involvement subscale (referred to here as AS, actual style) is one item rated by selecting one of five ordinal 
categories describing involvement (I made the final decision, I made the final decision after seriously considering my clinicians opinion, My clinician and I shared responsibility for making the best decision for me, My clinician made the final decision but seriously considered my opinion, My clinician made the final decision), scored as Active (patient made the decision; categories 1 and 2), Shared (category 3) or Passive (categories 4 and 5). Psychometric evaluation indicates adequate convergent and divergent validity (24). The Satisfaction sub-scale comprises six items (for example, "I am satisfied that I am adequately informed about the issues important to the decision") each rated on a five-point Likert scale from 1 (Strongly Disagree) to 5 (Strongly Agree). The Satisfaction sub-scale score is the mean of all items categorised into Low (1-3), Medium (3.01-4.0) or High (4.01-5) satisfaction.

Two clinician-rated measures were used. The Health of the Nation Outcome Scale is a 12-item measure of social disability yielding a total score ranging from 0 (low disability) to 48 (25). The Global Assessment of Functioning is a single-item measure of symptomatology and social functioning ranging from 0 (low functioning) to 100 (superior functioning) (26). One clinician-rated and patient-rated measure was used. The Camberwell Assessment of Need Short Appraisal Schedule (CANSAS) is a measure of unmet need in 22 health and social domains with scores ranging from 0 (no unmet needs) to $22(27)$.

\section{Procedure}

Prior to recruitment ethical approval was obtained at all sites. A convenience sample of patients were recruited from mental health teams across the sites. Clinicians identified potential patient participants, who were screened for severe mental illness (defined through diagnosis, disability and duration (28)) using a researcher 
confirmation of mental disorder as the main diagnosis using the SCID-CV in a researcher-rated case note review, a clinician-rated TAG of $>5$ and duration of mental illness $\geq 2$ years. The referring clinician asked patients who met inclusion criteria to assent to researcher contact. A researcher then met the patient, explained the study and obtained signed informed consent. CDMS-P and CANSAS were completed. The patient nominated a paired clinician of any profession whom they saw regularly, and identified the most important decision from their last meeting with the nominated clinician. CDIS was completed in relation to this decision. Nominal remuneration was offered at some sites dependent upon local ethical guidelines. The paired clinician was then approached by the researcher, who explained the study and obtained signed informed consent. The clinician completed CDMS-S, HoNOS and GAF in relation to their most recent meeting, generally within the last two weeks.

\section{Analysis}

Data were analysed using SPSS 19 and STATA 11.2. The level of statistical significance was set at 0.05 . Differences between excluded (no satisfaction data) and included participants were analysed using chi-squared and t-tests as appropriate (all variables were approximately normally distributed). Variables were created to describe the relationship between patient desired and received involvement (preference) and between patient and clinician desired style (agreement). We then used these variables as predictors of the outcome Satisfaction.

For the Preference hypothesis, a variable with three categories was created. Patients in the Disempowered category had a lower received involvement score than their desired involvement score (i.e. AS lower than DS-P, both rated on the same 0-4 scale). Those in the Empowered category had the contrary (i.e. AS more active than 
DS-P) and in the Matched category received their desired involvement level (i.e. AS same as DS-P). Thus, differences in Satisfaction between these categories would be due to patients' reported differences between desired and received involvement. A similar variable was created for the agreement hypothesis but describing the difference between clinician and patient reported Involvement (i.e. differences between the DS-S and DS-P). The categories were Clinician Disempowers, Agreement, and Clinician Empowers. Thus any differences in Satisfaction would be due to the differences between patient and clinician desired decision making style.

To test the hypotheses we used ordinal logistic regression models due to the ordered nature of the Satisfaction outcome. The models included a random effect to control for clustering by clinician under the assumption that the patient observations were not strictly independent if their relationship was with the same clinician. Sociodemographic, clinical and professional variables are known to be associated with satisfaction (i.e. are possible confounding factors) (29), so consistent with the research reviewed earlier, covariates were: ethnicity, age, diagnosis, duration of illness and illness severity measured by the TAG (as these influence CDM); gender and level of education (for sociodemographic completeness); service user rated unmet needs (CANSAS) and clinician-rated HONOS (as clinicians report concern over-using SDM with more severely unwell service users) and marital status and clinician type and years of experience (as these significantly differed between participants with and without satisfaction scores). Thus, the conditional effects are reported i.e. adjusted for these other possible explanatory factors. These covariates were retained in the model using a stepwise procedure if $p<0.1$ for continuous variables or likelihood ratio test $p<0.1$ for categorical variables. Centre was included in the models to reflect the sampling design of the study, with Ulm (Co-ordinating 
centre) as reference group. Model fit was assessed using the Brant test of the parallel regression assumption (30) and examination of the variance inflation factors for the covariates.

\section{Results}

A total of $445(76 \%)$ of the 588 patient participants in the CEDAR study were included in these analyses. Reasons for exclusion were not making a decision at most recent meeting $(n=122)$ and missing satisfaction subscale data $(n=21)$. Included participants were more likely to be older (42.5 vs. 39.2 years, $t(586)=-3.21$, $\mathrm{p}=0.001)$, married $\left(\chi^{2}(1)=4.22 \mathrm{p}=0.040\right)$ and preferred more active involvement $\left(\chi^{2}(2)=14.55, p=0.001\right)$

Clinical and sociodemographic characteristics of patient participants are shown in Table 1.

\section{Insert Table 1 here}

The 171 nominated clinicians comprised 64 psychiatrists, 31 nurses, 16 psychologists, 13 support workers, 13 non-psychiatrist doctors, 10 social workers, 7 healthcare assistants and 12 other (5 missing). Mean age was 46 years (SD 10.6), 102 were women (65 men and 4 missing) and mean length of time working in mental health services was 15.3 years (SD 9.7). 72 of these clinicians had more than one patient included. Clinicians paired with included patients differed from those paired with excluded patients in having worked for longer in mental health services (15.3 vs. 


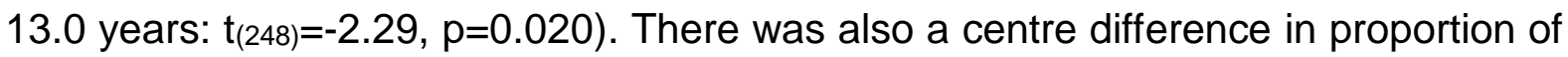
included patients $\left(\chi^{2}(5)=75.41, p<0.001\right)$.

Patients reported discussing 3.6 topics per meeting, with the most frequent being medication (77.5\%), symptoms (73.5\%) and family (70.1\%). Staff reported discussing 4.2 topics per meeting, with the most frequent being symptoms $(85.8 \%)$, medication $77.0 \%)$ and family (75.2\%) (31). The preference and agreement variables created to test the hypotheses were not highly correlated (Cohen's kappa $=0.16$ ).

Preference hypothesis

The first part of Table 2 shows the relationship between desired and experienced CDM style.

\section{Insert Table 2 here}

A total of $90(20 \%)$ patients were Disempowered, $190(43 \%)$ Matched their desired style, and $162(37 \%)$ were Empowered. The first part of Table 3 shows the relationship between these categories and satisfaction.

\section{Insert Table 3 here}

The ordinal logistic regression model of Satisfaction on Preference including a random effect for clustering by clinician is shown in Table 4. A likelihood-ratio test between this model and a model excluding Preference was significant $\left(\chi^{2}(2)=8.24\right.$, 
$p=0.016)$, providing evidence that there were differences between the Preference categories.

\section{Insert Table 4 here}

Disempowered patients were more likely to have lower satisfaction than those who Matched their desired level of involvement $(\mathrm{OR}=0.54, \mathrm{p}=0.041)$. Empowered patients were more likely to have higher satisfaction rating than those who were Disempowered $(\mathrm{OR}=2.47, \mathrm{p}=0.005)$. Older age was associated with higher satisfaction $(O R=1.04, p=0.002)$ and differences between the sites were found. Having more unmet needs was associated with lower satisfaction $(O R=0.86$, $\mathrm{p}<0.001)$. The Brant test and examination of Variance Inflation Factors (VIF) showed no evidence of violations in the model assumptions.

\section{Agreement hypothesis}

The second part of Table 2 shows the relationship between clinician and patient preference for CDM style. A total of 75 (17\%) were coded as Clinician Disempowers, $264(61 \%)$ as Agree and 91 (21\%) as Clinician Empowers. The second part of Table 3 shows the relationship between these categories and satisfaction.

Results from the ordinal regression model are provided in Table 5. A Likelihood-ratio test provided evidence that Satisfaction differed significantly between these Agreement categories $\left(\chi^{2}(2)=11.43, p=0.003\right)$. 
The model provided evidence that patients were significantly more likely to have higher satisfaction if they were in the Clinician Empowers compared to those in the Agree ( $\mathrm{OR}=2.44, \mathrm{p}=0.003)$ group, and compared to the Clinician Disempowers group ( $\mathrm{OR}=3.17, \mathrm{p}=0.003$ ). No evidence was found to indicate a significant difference in satisfaction scores between Agree and Clinician Disempowers groups $(p=0.397)$. Older age $(O R=1.04, p=0.005)$ and having fewer unmet needs $(O R=0.86$, $p<0.001)$ were associated with higher satisfaction scores, and differences were found between the sites. A Brant test showed that the assumptions of the model were not violated. Variance Inflation Factors (VIF) were examined and no variables caused violations of collinearity.

\section{Discussion}

This naturalistic observational study across six countries produced two key findings. First, patients who experienced more involvement in CDM than they desired rated higher satisfaction with CDM. Second, decisions made with clinicians whose decision-making style preference was for more active involvement than the patient preference were rated with higher satisfaction. Overall, more active involvement in decision-making than the patient stated as desired was associated with higher satisfaction. These results suggest that active decision-making, in which the patient makes the decision informed by the clinician, might be a more empirically defensible default style for clinicians to adopt than the currently advocated shared decision making (panel).

\section{Shared decision-making and satisfaction}


SDM is currently advocated as the optimal approach to CDM, with research showing good outcomes such as increased adherence (32). CDM intervention research has therefore focussed on SDM promotion. For example, Loh and colleagues showed better participation, satisfaction, adherence and involvement for an SDM intervention of physician training and a patient centred decision aid (7).

However patients do not always want SDM. A US general population survey of over 3,200 people found that though SDM was preferred by the majority $(62 \%)$, nearly a third (28\%) preferred active and some (9\%) stated a preference for passive CDM styles (33). Similarly, not all clinicians agree with or implement SDM. Psychiatrists perceive medical and legal decisions as inappropriate to share with patients with a diagnosis of schizophrenia (8), and are concerned about using SDM with patients who are acutely unwell, even though research has found that it is possible (15). Indeed, inpatients with schizophrenia have been found to desire SDM more than primary care patients (6). Given this ambivalence, it is unsurprising that SDM is not yet routine (34).

Patient satisfaction is an increasingly used outcome in mental health service evaluation (35), and has been shown to be impacted on through SDM interventions (36). For example, Loh and colleagues found that satisfaction increased for patients in their SDM intervention (7), indicating that more active decision-making styles lead to more satisfaction. Our findings showed that more active decision-making than desired did not decrease satisfaction compared to those that align, indeed $60 \%$ of Empowered (i.e. non-alignment in favour of increased patient involvement) patients rated high satisfaction, compared with $52 \%$ of aligned patients and $40 \%$ of Disempowered patients. 
When a patient makes a decision with a clinician who desires the same or more active CDM they are more satisfied with that decision (37). Previous research has shown that clinicians are concerned about mental health patients participating in some decisions (8), and that patients CDM preferences are not often sought (38). However in this study only $25 \%$ of clinicians preferred Passive CDM (where the clinician makes the decision). Our study did not investigate if clinicians had sought or considered patient preferences.

Regression for both hypotheses resulted in the same covariates: centre, patient age and unmet needs. Patient-rated needs have been found to be an important outcome domain. Junghan and colleagues found that reducing patientrated unmet need improved therapeutic alliance (39), and Catty and colleagues found met needs to be a predictor of therapeutic relationship (40). Similarly, patient ratings of unmet need have a causal relationship with quality of life - meeting needs leads to a subsequent improvement in quality of life (41). Patient age was linked to active decision-making by Hamann and colleagues (6). It may be that older patients are more likely to have been in the mental health services for longer and so may have different expectations and experiences of CDM, or developmentally have higher overall levels of satisfaction.

\section{Strengths and limitations}

The main strength of the study is its large, varied, multi-site sample recruited within routine mental health services. There is variety within the sample: of centre; within patients of diagnosis and within clinicians of profession. The patient participants in the CEDAR study all have severe mental illness, $44 \%$ with psychosis, a group whom clinicians have discussed concern over SDM (8). As a naturalistic study, patients 
rated any type of decision they made with their clinician, rather than restricting to treatment decisions such as reviewed by Joosten et al (14).

Stepwise selection is not a completely reliable method for selecting the best model, partly due to the removal of cases with missing data. In our study, the 133 cases with missing data were mostly due to incomplete outcome (satisfaction) data due to not having made a decision. Candidate variables in each of the models were identified a priori based on theoretical associations with outcome measures to reduce the possibility of finding false positive associations.

The use of convenience sampling means that participants may not be representative, due to factors such as clinician bias in referral. Measures used were patient and clinician self-report and did not include independent observer ratings of involvement style. Edwards and Elwyn found patients of general practitioners remembered consultations as using active CDM style, whereas the same interactions were rated as shared by researchers from a videotape (37). An alternative methodology to reduce reporting bias is recording followed by researcher observation and ratings of decisions, as used in other studies $(34,37)$, although this may impact on decision-making processes. A cross-sectional study cannot differentiate cause and effect of preference, agreement and satisfaction. Finally, the extent to which the decision content impacted Preference and Agreement is unknown.

\section{Clinical and research implications}

Shared decision-making was associated with more satisfaction than passive decision-making, so SDM is a minimum level of patient involvement to recommend. However, a more empowering decision-making style in the clinician seems the most 
empirically defensible default position for increasing patient-rated satisfaction. This has implications for clinical education. For example, from a biomedical ethics perspective the findings suggest that greater emphasis should be put on promoting autonomy rather than the current emphasis on beneficence (42). The costs and benefits for both patients and clinicians following such a re-orientation would need investigation. More generally, the issue of how decisions are made is a proxy indicator for broader debates about the core purpose of mental health systems (43), and the implications of an orientation towards recovery (44) and well-being (45).

This observational study could underpin an intervention to train either or both of clinicians and patients to use more patient-led decision-making styles if additional evidence can show an effect of CDM style alignment on outcome beyond satisfaction. In relation to medication management, which can be problematic (46), this approach is used by the CommonGround healthcare technology (47).

Cultural context influences CDM preferences, satisfaction and implementation. The emergence of centre as a covariate in both models in this sixcountry study highlights the importance of contextual factors in decision processes. Local research is needed to inform policy and practice as the results of multi-centre studies about interpersonal or transactional variables such as decision-making may be particularly challenging to generalise. Specific questions of interest to further CDM research are the stability of patient preferences over time, the influence of diagnosis, decision topic and type of clinician on satisfaction, and the extent to which satisfaction with a decision is best understood as a cross-sectional variable linked to that specific interaction, or a longitudinal construct linked to helping alliance and trust in the relationship with the clinician. 
Overall, this study suggests that clinicians who prefer to empower are likely to have decision-making interactions that leave patients more satisfied. This points to the importance of the clinician's interpersonal style and role expectations as major influences on patient experience. The findings support an orientation towards shared decision-making as a defensible approach to calibrating involvement. A more challenging implication is that shared decision-making may not be sufficient, and the optimal style may be to support the highest possible level of patient involvement.

\section{Acknowledgements}

The CEDAR study is funded by a grant from the Seventh Framework Programme (Research Area HEALTH-2007-3.1-4 Improving clinical decision making) of the European Union (Grant no. 223290). CEDAR is a multi-centre collaboration between the Section Process-Outcome Research, Department of Psychiatry II, UIm University, Germany; the Section for Recovery, Institute of Psychiatry, King's College London, U.K.; the Department of Psychiatry, University of Naples SUN, Italy; the Unit for Psychiatric Research, Aalborg Psychiatric Hospital, Aarhus University Hospital, Denmark; the Medical and Health Science Center, Department of Psychiatry, University of Debrecen, Hungary; and the Department of General and Social Psychiatry, University of Zurich, Switzerland.

\section{Declaration of interests}

All authors declare no conflicts of interests. 
Table 1: Clinical and sociodemographic characteristics of patients $(n=445)$

\begin{tabular}{|lll|}
\hline & $\mathrm{N}$ & $\%$ \\
\hline Gender: Female & 240 & $54 \%$ \\
\hline Ethnicity & & \\
$\quad$ White & 425 & $96 \%$ \\
Black or other & 19 & $4 \%$ \\
\hline Highest completed level of education & & \\
$\quad$ Primary level or less & 108 & $24 \%$ \\
Secondary level & 197 & $44 \%$ \\
$\quad$ Tertiary education & 127 & $29 \%$ \\
\hline In paid employment & 88 & $20 \%$ \\
\hline Diagnosis category & & \\
Psychotic disorders & 196 & $44 \%$ \\
Mood disorders & 155 & $35 \%$ \\
Personality disorder & 53 & $12 \%$ \\
Other & 41 & $9 \%$ \\
\hline & Mean & $\mathrm{s.d}$ \\
\hline Age (years) & 42.5 & 10.4 \\
General schooling (years, N =439) & 10.5 & 1.9 \\
\hline Duration of illness (years) & 12.5 & 8.9 \\
TAG & 7.4 & 2.2 \\
GAF (N = 428) & 48.8 & 11.0 \\
HAS & 8.5 & 1.6 \\
CANSAS (patient-rated unmet needs, N = 436) & 3.3 & 3.0 \\
HoNOS (N = 416) & 15.4 & 6.27 \\
\hline
\end{tabular}


Table 2: Preference $(n=442)$ and Agreement $(n=430)$ about CDM style

\begin{tabular}{|c|c|c|c|c|c|c|c|c|c|}
\hline & \multicolumn{6}{|c|}{ SU Desired CDM style } & \multirow{2}{*}{\multicolumn{2}{|c|}{ Total }} \\
\hline & & \multicolumn{2}{|c|}{ Active } & \multicolumn{2}{|c|}{ Shared } & \multicolumn{2}{|c|}{ Passive } & & \\
\hline & & $\mathrm{N}$ & $\%$ & $\mathrm{~N}$ & $\%$ & $\mathrm{~N}$ & $\%$ & $\mathrm{~N}$ & $\%$ \\
\hline \multicolumn{10}{|l|}{ Preference } \\
\hline \multirow{3}{*}{$\begin{array}{l}\text { Experienced } \\
\text { CDM Style }\end{array}$} & Active & $27^{m}$ & 6 & $64 \mathrm{e}$ & 15 & $15^{\mathrm{e}}$ & 3 & 106 & 24 \\
\hline & Shared & $22^{\circ}$ & 5 & $113^{\mathrm{m}}$ & 26 & $83^{e}$ & 19 & 218 & 49 \\
\hline & Passive & $9^{d}$ & 2 & $59^{d}$ & 13 & $50 \mathrm{~m}$ & 11 & 118 & 27 \\
\hline & Totals & 58 & 13 & 236 & 53 & 148 & 34 & 442 & 100 \\
\hline \multicolumn{10}{|l|}{ Agreement } \\
\hline \multicolumn{10}{|l|}{ Clinician } \\
\hline Desired & Shared & 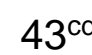 & 10 & $177^{a}$ & 41 & $68^{\mathrm{ce}}$ & 16 & 288 & 67 \\
\hline CDM Style & Passive & $3^{\text {cd }}$ & 1 & $29^{\text {cd }}$ & 7 & $77^{a}$ & 18 & 109 & 25 \\
\hline & Totals & 56 & 13 & 227 & 53 & 147 & 34 & 430 & \\
\hline
\end{tabular}

$\mathrm{d}=$ Disempowered, $\mathrm{m}=$ Matched, $\mathrm{e}=$ Empowered, $\mathrm{cd}=$ Clinician Disempowers, $\mathrm{a}=$ Agree, $\mathrm{ce}=$ Clinician Empowers 
Table 3: Satisfaction for different types of Agreement $(n=442)$ and Preference $(n=430)$

\begin{tabular}{|c|c|c|c|c|c|c|c|c|}
\hline & \multicolumn{6}{|c|}{ Satisfaction } & & \\
\hline & \multicolumn{2}{|c|}{ Low } & \multicolumn{2}{|c|}{ Medium } & \multicolumn{2}{|c|}{ High } & \multicolumn{2}{|c|}{ Total } \\
\hline & $\mathrm{N}$ & $\%$ & $\mathrm{~N}$ & $\%$ & $\mathrm{~N}$ & $\%$ & $\mathbf{N}$ & $\%$ \\
\hline \multicolumn{9}{|c|}{ Hypothesis 1 (Preference) } \\
\hline Disempowered & 12 & 13 & 42 & 47 & 36 & 40 & 90 & 100 \\
\hline Matched & 9 & 5 & 83 & 44 & 98 & 52 & 190 & 100 \\
\hline Empowered & 6 & 4 & 59 & 36 & 97 & 60 & 162 & 100 \\
\hline Total & 27 & 6 & 184 & 42 & 231 & 52 & 442 & 100 \\
\hline \multicolumn{9}{|c|}{ Hypothesis 2 (Agreement) } \\
\hline Clinician Disempowers & 11 & 15 & 30 & 40 & 34 & 45 & 75 & 100 \\
\hline Agree & 14 & 5 & 118 & 45 & 132 & 50 & 264 & 100 \\
\hline Clinician Empowers & 1 & 1 & 30 & 33 & 60 & 66 & 91 & 100 \\
\hline Total & 26 & 6 & 178 & 41 & 226 & 53 & 430 & 100 \\
\hline
\end{tabular}


Table 4: Multivariable ordinal logistic regression of Satisfaction on Decision making preference (difference between desired and received involvement)

$(n=442)$

\begin{tabular}{|c|c|c|c|c|c|}
\hline & \multirow{2}{*}{$\begin{array}{l}\text { Adjusted } \\
\text { Odds } \\
\text { Ratio }\end{array}$} & \multirow[t]{2}{*}{ SE } & \multirow{2}{*}{$\begin{array}{l}\mathrm{P} \text { (two- } \\
\text { tailed) }\end{array}$} & \multicolumn{2}{|c|}{$95 \% \mathrm{Cl}$} \\
\hline & & & & Lower & Upper \\
\hline \multicolumn{6}{|l|}{ Preference } \\
\hline Desired and received matched & Ref. & & & & \\
\hline Disempowered & 0.54 & 0.16 & 0.041 & 0.30 & 0.98 \\
\hline Empowered & 1.33 & 0.34 & 0.259 & 0.81 & 2.19 \\
\hline Patient age (years) & 1.04 & 0.01 & 0.002 & 1.02 & 1.07 \\
\hline \multicolumn{6}{|l|}{ Diagnosis } \\
\hline Psychotic disorders & Ref. & & & & \\
\hline Mood disorders & 0.94 & 0.27 & 0.817 & 0.54 & 1.63 \\
\hline Other diagnosis & 1.75 & 0.55 & 0.077 & 0.94 & 3.25 \\
\hline Duration of IIIness (years) & 0.97 & 0.01 & 0.060 & 0.94 & 1.00 \\
\hline TAG & 0.90 & 0.05 & 0.082 & 0.81 & 1.01 \\
\hline Unmet Needs (CANSAS) & 0.86 & 0.04 & $<0.001$ & 0.80 & 0.94 \\
\hline \multicolumn{6}{|l|}{ Co-ordinating centre } \\
\hline London & 1.98 & 1.03 & 0.189 & 0.71 & 5.50 \\
\hline Naples & 0.62 & 0.30 & 0.329 & 0.24 & 1.61 \\
\hline Debrecen & 1.19 & 0.65 & 0.756 & 0.41 & 3.47 \\
\hline Aalborg & 3.43 & 1.52 & 0.005 & 1.44 & 8.19 \\
\hline Zurich & 0.33 & 0.15 & 0.013 & 0.14 & 0.79 \\
\hline \multicolumn{6}{|l|}{ Agreement (Empowered v } \\
\hline Disempowered) & 2.47 & 0.79 & 0.005 & 1.32 & 4.63 \\
\hline
\end{tabular}


Table 5: Multivariable ordinal logistic regression of Satisfaction on Decision making agreement (difference between clinician and patient desired involvement) $(n=430)$

\begin{tabular}{|c|c|c|c|c|c|}
\hline & \multirow{2}{*}{$\begin{array}{l}\text { Adjusted } \\
\text { Odds } \\
\text { Ratio }\end{array}$} & \multirow[t]{2}{*}{ SE } & \multirow{2}{*}{$\begin{array}{l}\mathrm{P} \text { (two- } \\
\text { tailed) }\end{array}$} & \multicolumn{2}{|c|}{$95 \% \mathrm{Cl}$} \\
\hline & & & & Lower & Upper \\
\hline \multicolumn{6}{|l|}{ Agreement } \\
\hline Patient and Clinician agree & Ref. & & & & \\
\hline Clinician Disempowers (v & & & & & \\
\hline Agree) & 0.77 & 0.24 & 0.397 & 0.41 & 1.42 \\
\hline Clinician Empowers (v Agree) & 2.44 & 0.74 & 0.003 & 1.34 & 4.42 \\
\hline Patient age (years) & 1.04 & 0.01 & 0.005 & 1.01 & 1.07 \\
\hline \multicolumn{6}{|l|}{ Diagnosis } \\
\hline Psychotic disorders & Ref. & & & & \\
\hline Mood disorders & 0.97 & 0.28 & 0.909 & 0.55 & 1.70 \\
\hline Other diagnosis & 1.90 & 0.61 & 0.047 & 1.01 & 3.58 \\
\hline Duration of Illness (years) & 0.98 & 0.01 & 0.102 & 0.95 & 1.00 \\
\hline TAG & 0.88 & 0.05 & 0.033 & 0.79 & 0.99 \\
\hline Unmet Needs (CANSAS) & 0.87 & 0.04 & 0.001 & 0.80 & 0.94 \\
\hline \multicolumn{6}{|l|}{ Co-ordinating centre } \\
\hline Ulm & Ref. & & & & \\
\hline London & 2.66 & 1.43 & 0.069 & 0.93 & 7.62 \\
\hline Naples & 0.84 & 0.40 & 0.723 & 0.33 & 2.15 \\
\hline Debrecen & 1.23 & 0.67 & 0.710 & 0.42 & 3.59 \\
\hline Aalborg & 3.69 & 1.67 & 0.004 & 1.52 & 8.97 \\
\hline Zurich & 0.34 & 0.16 & 0.022 & 0.14 & 0.86 \\
\hline $\begin{array}{l}\text { Agreement (Clinician Empowers } \\
\text { v Clinician Disempowers) } \\
\text { Intraclass correlation coefficient }\end{array}$ & .24 & 1.24 & 0.003 & 1.48 & 6.82 \\
\hline
\end{tabular}




\section{References}

1. FENTON WS. Shared decision making: a model for the physician-patient relationship in the 21st century? Acta Psychiatr Scand. 2003;107:401-2.

2. GOSS C, MORETTI F, MAZZI MA, DEL PICCOLO L, RIMONDINI M, ZIMMERMANN C. Involving patients in decisions during psychiatric consultations. Br J Psychiatry. 2008;193:416-21.

3. BHUGRA D, EASTER A, MALLARIS Y, GUPTA S. Clinical decision making in psychiatry by psychiatrists. Acta Psychiatr Scand. 2011 Nov;124:403-11.

4. OWEN GS, SZMUKLER G, RICHARDSON G, et al. Decision-making capacity for treatment in psychiatric and medical in-patients: cross-sectional, comparative study. $\mathrm{Br} \mathbf{J}$ Psychiatry. 2013;203:461-7.

5. DUNCAN E, BEST C, HAGEN S. Shared decision making interventions for people with mental health conditions. Cochrane Database Syst Rev. 2010:CD007297.

6. HAMANN J, COHEN R, LEUCHT S, BUSCH R, KISSLING W. Do patients with schizophrenia wish to be involved in decisions about their medical treatment? AJ Psychiatry. 2005 Dec;162:2382-4.

7. LOH A, SIMON D, WILLS CE, KRISTON L, NIEBLING W, HARTER M. The effects of a shared decision-making intervention in primary care of depression: a clusterrandomized controlled trial. Patient Educ Couns. 2007;67:324-32.

8. HAMANN J, MENDEL R, COHEN R, et al. Psychiatrists' Use of Shared Decision Making in the Treatment of Schizophrenia: Patient Characteristics and Decision Topics. Psychiatr Serv. 2009;60:1107 - 12.

9. CHARLES C, GAFNI A, WHELAN T. Decision-making in the physician-patient encounter: revisiting the shared treatment decision-making model. Social science $\&$ medicine (1982). 1999 Sep;49:651-61.

10. BHUGRA D. Decision-making in psychiatry: what can we learn? Acta Psychiatr Scand. 2008;118:1-3.

11. MAKOUL G, CLAYMAN ML. An integrative model of shared decision making in medical encounters. Patient Educ Couns. 2006 Mar;60:301-12.

12. LEGARE F, RATTE S, STACEY D, et al. Interventions for improving the adoption of shared decision making by healthcare professionals. Cochrane Database of Systematic Reviews. 2010:CD006732.

13. CHEWNING B, BYLUND CL, SHAH B, ARORA NK, GUEGUEN JA, MAKOUL G. Patient preferences for shared decisions: a systematic review. Patient Educ Couns. 2012 Jan;86:9-18.

14. JOOSTEN EA, DEFUENTES-MERILLAS L, DE WEERT GH, SENSKY T, VAN DER STAAK CP, DE JONG CA. Systematic review of the effects of shared decision-making on patient satisfaction, treatment adherence and health status. Psychother Psychosom. 2008;77:219-26.

15. HAMANN J, LANGER B, WINKLER V, et al. Shared decision making for inpatients with schizophrenia. Acta Psychiatr Scand. 2006;114:265-73.

16. WOLTMANN EM, WILKNISS SM, TEACHOUT A, MCHUGO GJ, DRAKE RE. Trial of an electronic decision support system to facilitate shared decision making in community mental health. Psychiatr Serv. 2011 Jan;62:54-60.

17. DUNCAN E, BEST C, HAGEN S. Shared decision making interventions for people with mental health conditions. Cochrane database of systematic reviews (Online).

2010:CD007297.

18. NATIONAL INSTITUTE FOR HEALTH AND CLINICAL EXCELLENCE.

Psychosis and schizophrenia in adults: treatment and management. NICE Clinical Guideline 178. London: NICE; 2014. 
19. NATIONAL INSTITUTE FOR HEALTH AND CLINICAL EXCELLENCE. Service user experience in adult mental health: improving the experience of care for people using adult NHS mental health services. CG136. London: National Institute for Health and Clinical Excellence; 2011.

20. PUSCHNER B, NEUMANN P, JORDAN H, et al. Development and psychometric properties of a five-language multiperspective instrument to assess clinical decision making style in the treatment of people with severe mental illness (CDMS). BMC Psychiatry. 2013;13:48.

21. FIRST MB, SPITZER, R.L., GIBBON, M., WILLIAMS, J.B.W. Structured Clinical Interviews for DSM-IV Axis I Disorders - Clinical Version (SCID-CV). Washington, DC: American Psychiatric Press; 1997.

22. SLADE M, CAHILL S, KELSEY W, POWELL R, STRATHDEE G. Threshold 2: the reliability, validity and sensitivity to change of the Threshold Assessment Grid (TAG). Acta psychiatrica Scandinavica. 2002;106:453-60.

23. SLADE M, CAHILL, S., KELSEY, W., LEESE, M., POWELL, R., STRATHDEE, G. Threshold 4: an evaluation of the Threshold Assessment Grid as an aid to mental health referrals. Primary Care Mental Health. 2003;1:45-54.

24. SLADE M, JORDAN H, CLARKE E, et al. The development and evaluation of a five-language multi-perspective standardised measure: Clinical Decision-making Involvement and Satisfaction (CDIS). BMC Health Services Research. 2014; 14:323.

25. WING JK, BEEVOR AS, CURTIS RH, PARK SB, HADDEN S, BURNS A. Health of the Nation Outcome Scales (HoNOS). Research and Development. Br J Psychiatry. $1998 ; 172$ 11-8.

26. JONES SH, THORNICROFT G, COFFEY M, DUNN G. A brief mental health outcome scale: reliability and validity of the Global Assessment of Functioning (GAF). Br J Psychiatry. 1995;166:654-9.

27. PHELAN M, SLADE M, THORNICROFT G, et al. The Camberwell Assessment of Need: the validity and reliability of an instrument to assess the needs of people with severe mental illness. Br J Psychiatry. 1995;167:589-95.

28. SLADE M, POWELL R, STRATHDEE G. Current approaches to identifying the severely mentally ill. SocPsychiatry PsychiatrEpidemiol. 1997;32:177-84.

29. RUGGERI M, LASALVIA A, BISOFFI G, et al. Satisfaction with mental health services among people with schizophrenia in five European sites: results from the EPSILON Study. Schizophr Bull. 2003;29:229-45.

30. BRANT R. Assessing proportionality in the proportional odds model for ordinal logistic regression. Biometrics. 1990;46:1171-8.

31. KONRAD J, LOOS, S., NEUMANN, P., MAYER, B., SLADE, M., JORDAN, H., DE ROSA, C., DEL VECCIO, V., EGERHAZI, A., NAGY, M., KROGSGAARD BORDING, M., ØSTERMARK SØRENSEN, H., KAWOHL, W., RÖSSLER, W., PUSCHNER, B. . A five-language multiperspective instrument to assess clinical decision making in the routine care of people with severe mental illness. Journal of Mental Health. in press.

32. DRAKE RE, WILKNISS SM, FROUNFELKER RL, et al. The ThresholdsDartmouth partnership and research on shared decision making. Psychiatr Serv. 2009;60:1424.

33. MURRAY E, POLLACK L, WHITE M, LO B. Clinical decision-making: Patients' preferences and experiences. Patient Educ Couns. 2007 Feb;65:189-96.

34. MATTHIAS MS, SALYERS MP, ROLLINS AL, FRANKEL RM. Decision making in recovery-oriented mental health care. Psychiatr Rehabil J. 2012;35:305-14. 
35. RUGGERI M, LASALVIA A, SALVI G, CRISTOFALO D, BONETTO C,

TANSELLA M. Applications and usefulness of routine measurement of patients' satisfaction with community-based mental health care. Acta Psychiatr Scand Suppl. 2007:53-65.

36. MALM U, IVARSSON B, ALLEBECK P, FALLOON IR. Integrated care in schizophrenia: a 2-year randomized controlled study of two community-based treatment programs. Acta Psychiatr Scand. 2003 Jun;107:415-23.

37. EDWARDS A, ELWYN G. Inside the black box of shared decision making: distinguishing between the process of involvement and who makes the decision. Health Expect. 2006 Dec;9:307-20.

38. GOOSSENSEN A, ZIJLSTRA P, KOOPMANSCHAP M. Measuring shared decision making processes in psychiatry: skills versus patient satisfaction. Patient Educ Couns. 2007;67:50-6.

39. JUNGHAN UM, LEESE M, PRIEBE S, SLADE M. Staff and patient perspectives on unmet need and therapeutic alliance in community mental health services. Br J Psychiatry. 2007;191:543-7.

40. CATTY J, WHITE S, KOLETSI M, et al. Therapeutic relationships in vocational rehabilitation: predicting good relationships for people with psychosis. Psychiatry Res. 2011;187:68-73.

41. SLADE M, LEESE M, CAHILL S, THORNICROFT G, KUIPERS E. Patient-rated mental health needs and quality of life improvement. Br J Psychiatry. 2005;187:256-61.

42. BEAUCHAMP T, CHILDRESS J. Principles of Biomedical Ethics. Oxford: Oxford University Press; 2001.

43. PRIEBE S, BURNS T, CRAIG TK. The future of academic psychiatry may be social. Br J Psychiatry. 2013;202:319-20.

44. LEAMY M, BIRD V, LE BOUTILLIER C, WILLIAMS J, SLADE M. A conceptual framework for personal recovery in mental health: systematic review and narrative synthesis. Br J Psychiatry. 2011;199:445-52.

45. SCHRANK B, BIRD, V., TYLEE, A., COGGINS, T., RASHID, T., SLADE, M. . Conceptualising and measuring the well-being of people with psychosis: systematic review and narrative synthesis. Soc Sci Med. 2013;92:9-21.

46. SYLVIA LG, REILLY-HARRINGTON NA, LEON AC, et al. Medication adherence in a comparative effectiveness trial for bipolar disorder. Acta Psychiatr Scand. 2014;129:35965.

47. STEIN BD, KOGAN JN, MIHALYO MJ, et al. Use of a Computerized Medication Shared Decision Making Tool in Community Mental Health Settings: Impact on Psychotropic Medication Adherence. Community Ment Health J. 2013;49:185-92. 